
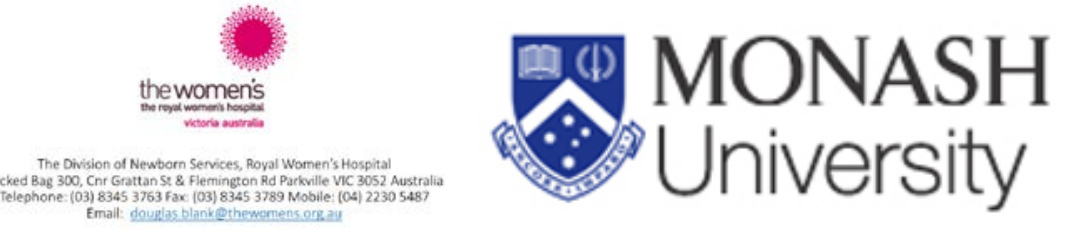

\title{
Lung Ultrasound Accurately Detects Pneumothorax in a Preterm Newborn Lamb Model
}

Running title: Lung US for diagnosis of pneumothorax

Douglas A Blank MD ${ }^{1,2}$, Stuart B Hooper $\mathrm{PhD}^{2}$, Corinna Binder-Heschl MD², Martin Kluckow MBBS PhD ${ }^{3}$, Andrew W Gill BM ${ }^{4}$, Domenic LaRosa BSc (Hons) ${ }^{2}$, Ishmael Inocencio BBMS (Hons) ${ }^{2}$, Ali Moxham BSc (Hons) ${ }^{2}$, Karyn Rodgers ${ }^{2}$, Valerie Zahra BSc (Hons) ${ }^{2}$, Peter G Davis MD ${ }^{1}$, and Graeme R Polglase PhD ${ }^{2}$

${ }^{1}$ Newborn Research Centre, The Royal Women's Hospital, Melbourne, Victoria, Australia

${ }^{2}$ The Hudson Institute of Medical Research, Monash University, Clayton, Victoria, Australia

${ }^{3}$ Department of Neonatology, Royal North Shore Hospital and University of Sydney, Sydney, Australia

${ }^{4}$ Centre for Neonatal Research and Education, University of Western Australia, Perth, Australia

${ }^{5}$ Department of Neonatology, Medical University of Graz, Graz, Austria

Address for correspondence and reprints:

Dr Douglas Blank, MD, Newborn Research Fellow

MIMR-PHI Institute of Medical Research, The Hudson Institute of Medical Research

Department of Obstetrics and Gynaecology, Monash University

27-31 Wright Street, Clayton, 3168, Victoria, Australia

Email: douglas.blank@thewomens.org.au or blankdouglas@gmail.com

Mobile: +61 0422305487

This is the author manuscript accepted for publication and has undergone full peer review but has not been through the copyediting, typesetting, pagination and proofreading process, which may lead to differences between this version and the Version of Record. Please cite this article as doi: 10.1111/jpc.13154

This article is protected by copyright. All rights reserved. 


\section{ABSTRACT:}

Aim: Pneumothorax is a common emergency affecting extremely preterm. In adult studies, lung ultrasound has performed better than chest $\mathrm{x}$-ray in the diagnosis of pneumothorax. The purpose of this study was to determine the efficacy of lung ultrasound (LUS) examination to detect pneumothorax using a preterm animal model.

Methods: This was a prospective, observational study using newborn Border-Leicester lambs at gestational age $=126$ days (equivalent to gestational age $=26$ weeks in humans) receiving mechanical ventilation from birth to 2 hours of life. At the conclusion of the experiment, LUS was performed, the lambs were then euthanized, and a post-mortem exam was immediately performed. We used previously published ultrasound techniques to identify pneumothorax. Test characteristics of LUS to detect pneumothorax were calculated, using the post-mortem exam as the "gold standard" test.

Results: Nine lambs (18 lungs) were examined. Four lambs had a unilateral pneumothorax, all of which were identified by LUS with no false positives.

Conclusions: This was the first study to use post-mortem findings to test the efficacy of LUS to detect pneumothorax in a newborn animal model. Lung ultrasound accurately detected pneumothorax, verified by postmortem exam, in premature, newborn lambs.

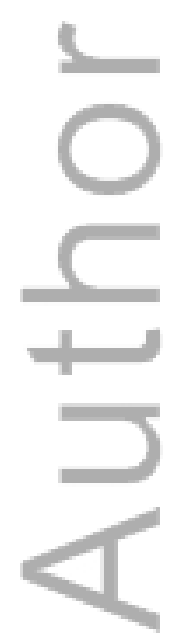


What is already known on this topic:

- Pneumothorax is a frequently encountered newborn emergency, chest x-ray is the currently preferred mode of diagnosis.

- Adult studies have demonstrated lung ultrasound performs better than chest $\mathrm{x}$-ray to diagnose

= pheumothorax in emergency room settings.

What this paper adds:

- Lung ultrasound can accurately detect pneumothorax, verified by post-mortem examination, in premature ventilated newborn lambs.

- We have described a novel gold standard technique for evaluating air leak syndromes on postmortem examination in an animal model.
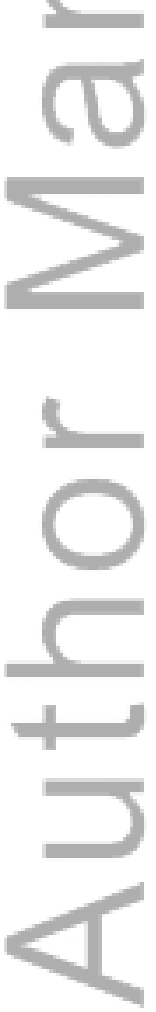

This article is protected by copyright. All rights reserved. 


\section{INTRODUCTION}

The risk of pneumothorax is highest during the first 48 hours of life. In large trials of extremely low gestational age newborns, the incidence of pneumothorax was $7-9 \%$ with $79 \%$ of the air leaks occurring in the first 48 hours of life.[1-3] In ā study of term babies with severe respiratory distress shortly after birth, the incidence of pneumothorax at entry into the trial was 19\%.[4] Pneumothorax places babies at increased risk for death and significant morbidities and prompt recognition of pneumothorax is desirable.[5]

In the delivery room, the Neonatal Resuscitation Program recommends consideration of pneumothorax if extensive resuscitation is required for a baby with bradycardia, but does not recommend clinical signs or tests to aide in the diagnosis of pneumothorax in the delivery room.[6, 7] Lung ultrasound (LUS) potentially offers a superior alternative to $\mathrm{x}$-ray for the diagnosis of pneumothorax because it can be performed and interpreted by the treating clinician at the bedside, can be easily repeated, and does not expose the baby to radiation.

Ultrasound beams penetrating a fluid filled lung create ultrasound images as the density of fluid changes between the pleural line and the lung parenchyma. The attenuation of sound waves caused by air in the lungs has discouraged the use of lung ultrasound. However, ultrasound beams passing through an aerated lung will produce characteristic artifacts that are now recognized as having diagnostic importance.[8-10]

Standard lung ultrasound signs have been established in adult studies using CT scans for validation and all signs arise from the pleural line.[8, 9, 11-14] In a well aerated lung, the pleural line is bright because of the difference in acoustic impedance between the visceral pleura and the aerated lung parenchyma.[9] This reflector is at 90 degrees to the angle of insonation and may give rise to a reverberation artifact, A-lines, whereby the pleural line is regularly repeated through the depth of the ultrasound window. In a pneumothorax the discrepant acoustic boundary occurs between the parietal pleura and the pleural air, producing strong reverberation artifact represented as A-lines. Healthy lung is seen as the "seashore sign" on M-mode or characteristic movement of the pleural line with respiration in 2-D clips called lung sliding. If there is a pneumothorax, only A-lines are seen and lung sliding is obliterated. The "seashore sign" is replaced with a "stratosphere sign" (figure 1). The primary aim of 
this study was to determine the accuracy of lung ultrasound in detecting a pneumothorax in a ventilated preterm, newborn lamb model.

\section{METHODS}

This was a prospective observational study of premature, newborn lambs with a gestational age of 126 days (equivalent to 26 weeks gestation in humans) conducted at the Hudson Institute at Monash University. The experimental protocol was performed in accordance with guidelines established by the National Health and Medical Research Council of Australia and was approved by the Monash Medical Centre animal ethics committee.

\section{Surgical preparation}

At $126 \pm 2$ days gestation Border-Leicester ewes were anaesthetised with an intravenous bolus of $5 \%$ sodium thiopentone (Pentothal; $1 \mathrm{~g}$ in $20 \mathrm{ml}$ ) and, following intubation, maintained with inhalation of $1.5-3 \%$ halothane in air. The fetal head and neck were exposed via hysterotomy for surgical insertion of carotid artery flow catheters, jugular vein catheters, and oral intubation with a 4.0 cuffed endotracheal tube (Coviden, Dublin, Ireland). Immediately after instrumentation, lambs were delivered surgically, quickly weighed then moved to a warming bed, dried, and ventilation initiated. The lambs were enrolled in a primary study of ventilator associated lung injury.

All lambs received a 30 second sustained inflation of $35 \mathrm{cmH}_{2} \mathrm{O}$ (Neopuff; Fisher \& Paykel, Auckland, New Zealand) followed by an injurious ventilation strategy consisting of 15 minutes of ventilation with pressures of 40/0 $\mathrm{cmH}_{2} \mathrm{O}$ at a rate of 60 breaths per minute, followed by 105 minutes of volume guarantee ventilation of $7 \mathrm{ml} / \mathrm{kg} /$ breath with a positive end expiratory pressure of $5 \mathrm{cmH}_{2} \mathrm{O}$ (Babylog 8000 , Dräger, Lübeck, Germany). Ventilator rate and peak inspiratory pressure were titrated to achieve a $\mathrm{PaCO}_{2}$ of $35-60$. Lambs were ventilated with warmed, humidified gas starting at a $\mathrm{FiO}_{2}$ of 0.21 , which was adjusted to targeted pre-ductal transcutaneous oxyhemoglobin saturation of 85-95\% from 5 minutes of age (Radical 7, Massimo, California, USA). The lambs did 
not receive prenatal steroids prior to delivery and surfactant was not administered. Alfaxalone in $4 \%$ glucose was administered by continuous infusion for anesthesia, analgesia and suppression of spontaneous breathing.

\section{Lung Ultrasound Examination}

LUS exams were conducted prior to $60 \mathrm{~min}$, at $90 \mathrm{~min}$, and at $2 \mathrm{~h}$ of life. We used previously published ultrasound techniques to identify pneumothorax (stratosphere sign on M-mode, lack of lung sliding, and the presence of Alines with a lack of B-lines on 2-D images).[8, 9, 11-14] The Philips Compact Extreme Ultrasound Machine (CX50, Koninklijke Philips, Netherlands) was used to collect images, using L12-3, S12-4, and C5-1 probes, with the L12-3 preferred when available. In order to minimize interference with the primary experiment, we did not compare images from different probes on the same animal. The initial settings for the examinations were a depth of $4 \mathrm{~cm}$ for all probes, a gain of 100 for the L12-3, 75 for the $\mathrm{C} 5-1$, and 60 for the S12-4. Exams were performed with the lambs in the supine position. The ultrasonographers (DB, CB) examined the anterior lung fields with the probe positioned in a longitudinal orientation with the notch towards the lamb's head. The ultrasound exam consisted of capturing 2-D clips and M-mode images of the right upper and lower and left upper and lower anterior lung fields. The ultrasonographer performing the exam recorded the presence and location of the pneumothorax prior to autopsy.

\section{Post-mortem Examination}

Immediately after obtaining the images at $2 \mathrm{~h}$ the lambs were euthanized (sodium pentobarbitone i.v. $100 \mathrm{mg} / \mathrm{kg}$ ) and a post-mortem examination performed. The abdomen was carefully opened and the diaphragm inspected for tension pneumothorax, demonstrated by air causing downward displacement of the diaphragm.[15, 16] The chest was then opened, the lungs and trachea dissected and inspected for blebs (air pockets trapped beneath the visceral pleura), pulmonary interstitial emphysema (PIE), and other evidence of air leak. A cut 4.0 endotracheal tube (ETT) was inserted into the intact trachea, the cuff gently inflated and secured with suture to prevent air leak. A syringe was placed into the proximal end of ETT such that the entire system was air tight, the lungs were submerged in a clear container of water, and air was slowly injected in a stepwise fashion until a maximum 
volume of $10 \mathrm{ml} / \mathrm{kg}$ was obtained. A pneumothorax was positively identified if we observed downward displacement of the diaphragm after opening the abdomen (tension pneumothorax, figure 1) or if air bubbles were observed escaping during the bubble test (on-going leak, figure 2). In addition, we considered the autopsy positive for air leak syndrome if we noted pneumothorax, blebs or PIE on gross inspection of the lung performed both before and after the bubble test (figure 3).

\section{Statistical analysis}

Vital signs, respiratory parameters, and blood gas values in lambs before and after pneumothorax and in lambs without pneumothorax were compared using a one-way ANOVA. Means with SD are reported for normally distributed continuous variables and medians with $25-75 \%$ interquartile ranges are reported when the distribution was not normal. The sensitivity, specificity, positive predictive value and negative predictive value of LUS to detect pneumothorax were tested using the post-mortem exam results as the "gold stand" test. Each lung was considered individually. To test inter-rater reliability, two expert ultrasonographers, who were not present during data collection, (MK, AG) independently evaluated images obtained from each hemi-thorax of all subjects and graded the images "yes" or "no" for the presence of pneumothorax blinded to the post-mortem result. Statistical significance was accepted as $p<0.05$. Stata software was used for statistical analysis (StataCorp, Texas, USA).

\section{RESULTS}

Nine lambs were included in the study. The median weight was $2.5 \mathrm{~kg}$ (IQR 2.4-2.7) and four of the lambs were males. There were no demographic differences of the lambs between those who developed pneumothorax and those that did not. LUS correctly identified all 4 cases of pneumothorax, with no false positives. The sensitivity, specificity, negative predictive value and positive predictive value for pneumothorax were 100\% (table 1). All cases of pneumothorax involved the upper and lower lung fields and in all cases both 2-D clips (showing A-lines with a lack of lung sliding) and M-mode (showing a "stratosphere" sign) were positive. The contralateral lung was negative on LUS and autopsy in all cases. The primary experiment allowed for one attempt at drainage of the pneumothorax via needle aspiration. Therefore, needle aspiration was attempted in 3 of the 4 identified 
pneumothoraxes with transient improvement in $\mathrm{HR}, \mathrm{SpO}_{2}$, and MAP. The $4^{\text {th }}$ lamb had the pneumothorax identified at the time of scheduled euthanasia, so needle decompression was not attempted.

On post-mortem examination, 3 cases of pneumothorax were confirmed as tension pneumothorax with downward displacement of the diaphragm seen when opening the abdomen. In the final case of tension pneumothorax, needle aspiration resulted in $80 \mathrm{~mL}$ of air was drained with immediate improvement in bradycardia, hypoxia, and hypotension until the experiment concluded 8 minutes later. Autopsy showed a positive bubble test, confirming ongoing air leak.

In addition to the 4 cases of correctly identified pneumothorax, there were 2 cases of non-pneumothorax air leak syndrome that were not detected on LUS. One lamb had PIE involving the posterior aspect of the left upper lobe (Figure 3, A \& B). A second had a bleb involving the superior posterior aspect of the left lower lobe (Figure 3, C \& D). In both cases the bubble test for ongoing air leak was negative. There were no false positive LUS exams. No subject had bilateral air leak syndromes on autopsy. Two expert ultrasonographers (MK, AG) independently identified all four pneumothoraxes without any false positives after evaluation of 34 images each.

\section{Comparison of physiologic parameters}

Comparisons of physiologic parameters between lambs prior to pneumothorax, lambs after pneumothorax was recognized on LUS, and lambs that never developed pneumothorax are presented in table 2. There were no significant differences in any variable between the lambs that never developed pneumothorax to the lambs prior

to pneumothorax. A pneumothorax resulted in a significantly lower heart rate, saturation of peripheral oxygen, and mean arterial blood pressure and a higher alveolar-arterial concentration of oxygen gradient compared to values prior to the pneumothorax.
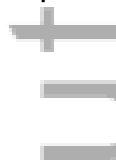

\section{DISCUSSION}


The validity of ultrasound to detect pneumothorax in preterm neonates is unknown. We have shown that LUS can accurately detect a ventilator associated pneumothorax in an animal model that represents extremely low gestational age newborns. This is the first study that has used an immediate post-mortem examination to verify an air leak syndrome in newborns. We performed the post-mortem immediately following the conclusion of the experiment, completing the examination of the lungs within 30 min of euthanasia. By viewing the diaphragm from an inferior approach we could reliably detect a tension pneumothorax. We believe our bubble test technique functions as an adequate confirmatory test to exclude a pneumothorax which is not under tension.

Two lungs demonstrated non-pneumothorax air leak syndromes (PIE and bleb). These were not misclassified as pneumothorax by LUS exams. In both cases the bubble test for an ongoing air leak was negative. Future studies are needed to differentiate between air leak syndromes that warrant treatment and those that warrant observation.

In newborns, lung ultrasound has been reported to predict which babies will need admission to the NICU, surfactant, reduce the number of x-rays taken, and can characterize the appearance of transient tachypnea of the newborn, meconium aspiration syndrome, and the appearance of the lungs after surfactant administration.[10, 1722] Lung ultrasound has been used by emergency and intensive care services to diagnose, characterize, and treat pneumothorax in adult populations.[12-14, 23-25] Using CT scans as the gold standard to diagnose pneumothorax, recent meta-analyses have confirmed that lung ultrasound was superior to x-ray.[23, 24] The accuracy of lung ultrasound to diagnose and characterize pneumothorax compared favorably to CT scan in an adult porcine model.[11, 26]

\section{Limitations}

There were several limitations of this study. The incidence of air leak syndromes in our study was higher than would be expected in the NICU because our subjects received an injurious ventilation strategy. We used an immediate post-mortem exam as a gold standard for diagnosing pneumothorax. We believe that an immediate post-mortem exam is valid and easy to interpret. However, we are the first to report diagnosis of pneumothorax 
employing this technique. Our subjects had severe respiratory distress syndrome (RDS). It may be easier to distinguish between a lung with severe RDS and pneumothorax than a lung with mild RDS and a pneumothorax. We did not compare trans-illumination or chest x-ray to LUS. Trans-illumination has been shown to be an accurate method to diagnose pneumothorax in neonates using chest x-ray as the gold standard.[27-29] Ultrasound may be superior to trans-illumination in newborns with more subcutaneous fat and muscle or edema, but we did not make that comparison. Addressing the limitations of this study will serve as the basis for improvement of future studies to test the accuracy of LUS in diagnosis of air leak syndromes.

In conclusion, lung ultrasound can accurately detect pneumothorax, verified by post-mortem examination, in premature ventilated newborn lambs. We have described a novel gold standard technique for evaluating air leak syndromes on post-mortem examination in an animal model. Future studies in both humans and in animal models are warranted to further explore the potential utility of LUS in the detection and treatment of pneumothorax.

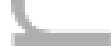

Conflicts of interest: The authors have no conflicts of interest to report or financial ties to products in the study. This research was supported by National Institutes of Health R01HD072848-01A1, an AVANT Innovative Research Grant awarded by the Research Foundation of Cerebral Palsy Alliance, NHMRC Research Fellowships, a Rebecca L. Cooper Medical Research Foundation Fellowship and the Victorian Government's Operational Infrastructure Support Program. Dr. Binder-Heschl is supported by the Austrian Science Fund (FWF).

List of abbreviations: LUS=Lung ultrasound, PIE=Pulmonary interstitial emphysema, ETT=Endotracheal tube, RDS=Respiratory distress syndrome, PTX=Pneumothorax.

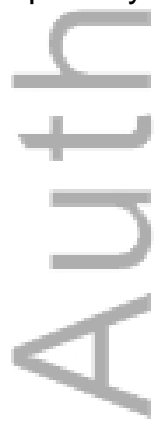


References:

1. Network SSGotEKSNNR, Finer NN, Carlo WA, Walsh MC, Rich W, Gantz MG, et al. Early CPAP versus surfactant in extremely preterm infants. The New England journal of medicine. 2010;362(21):1970-9. doi: 10.1056/NEJMoa0911783. PubMed PMID: 20472939; PubMed Central PMCID: PMC3071534.

2. Morley C, Davis PG, Doyle L, Hascoet JM, Carlin JB. Nasal CPAP or intubation at birth for very preterm infants. The New England journal of medicine. 2008;(358):700-8.

3. Bhatia R, Davis PG, Doyle LW, Wong C, Morley CJ. Identification of pneumothorax in very preterm infants. The Journal of pediatrics. 2011;159(1):115-20 e1. doi: 10.1016/j.jpeds.2010.12.016. PubMed PMID: 21300372.

4. Ehrenkranz RA, Finer N. Inhaled nitric oxide in full-term and near full-term infants with hypoxic respiratory failure. The New England journal of medicine. 1997;336(9).

5. Duong HH, Mirea L, Shah PS, Yang J, Lee SK, Sankaran K. Pneumothorax in neonates: Trends, predictors and outcomes. Journal of neonatal-perinatal medicine. 2014;7(1):29-38. doi: 10.3233/NPM-1473813. PubMed PMID: 24815703.

6. Kattwinkel J, Perlman J. The Neonatal Resuscitation Program: The Evidence Evaluation Process and Anticipating Edition 6. NeoReviews. 2010;11(12):e673-e80. doi: 10.1542/neo.11-12-e673.

7. Kattwinkel J, Perlman JM, Aziz K, Colby C, Fairchild K, Gallagher J, et al. Neonatal resuscitation: 2010 American Heart Association Guidelines for Cardiopulmonary Resuscitation and Emergency Cardiovascular Care. Pediatrics. 2010;126(5):e1400-13. doi: 10.1542/peds.2010-2972E. PubMed PMID: 20956432.

8. Lichtenstein D. Lung ultrasound in the critically ill. Current opinion in critical care. 2014;20(3):315-22. doi: 10.1097/MCC.0000000000000096. PubMed PMID: 24758984. 
9. Lichtenstein DA, Mauriat P. Lung Ultrasound in the Critically III Neonate. Current pediatric reviews. 2012;8(3):217-23. doi: 10.2174/157339612802139389. PubMed PMID: 23255876; PubMed Central PMCID: PMC3522086.

10. Raimondi F, Cattarossi L, Copetti R. International Perspectives: Point-of-Care Chest Ultrasound in the Neonatal Intensive Care Unit: An Italian Perspective. NeoReviews. 2014;15(1):e2-e6. doi: 10.1542/neo.15-1-e2.

11. Oveland NP, Lossius HM, Wemmelund K, Stokkeland PJ, Knudsen L, Sloth E. Using thoracic ultrasonography to accurately assess pneumothorax progression during positive pressure ventilation: a comparison with CT scanning. Chest. 2013;143(2):415-22. doi: 10.1378/chest.12-1445. PubMed PMID: 23188058; PubMed Central PMCID: PMC3566995.

12. Volpicelli G, Boero E, Sverzellati N, Cardinale L, Busso M, Boccuzzi F, et al. Semi-quantification of pneumothorax volume by lung ultrasound. Intensive care medicine. 2014;40(10):1460-7. doi: 10.1007/s00134014-3402-9. PubMed PMID: 25056671.

13. Lichtenstein DA, Menu Y. A bedside ultrasound sign ruling out pneumothorax in the critically ill. Lung sliding. Chest. 1995;108(5):1345-8. PubMed PMID: 7587439.

14. Lichtenstein D, Mezière G, Biderman P, Gepner A. The "lung point": an ultrasound sign specific to pneumothorax. Intensive care medicine. 2000;26(10):1434-40. doi: 10.1007/s001340000627.

15. Finkbeiner WE, Davis RL, Ursell PC, Elsevier Science (Firm), ScienceDirect (Online service). Autopsy pathology a manual and atlas. Philadelphia, PA: Saunders/Elsevier,; 2009. Available from: http://ezproxy.lib.monash.edu.au/login?url=http://www.sciencedirect.com/science/book/9781416054535 Full text available from ScienceDirect. 
16. Ludwig J, Kienzle GD. Pneumothorax in a large autopsy population. A study of 77 cases. American journal of clinical pathology. 1978;70(1):24-6. PubMed PMID: 696669.

17. Raimondi F, Migliaro F, Sodano A, Ferrara T, Lama S, Vallone G, et al. Use of neonatal chest ultrasound to predict noninvasive ventilation failure. Pediatrics. 2014;134(4):e1089-94. doi: 10.1542/peds.2013-3924. PubMed PMID: 25180278.

18. Raimondi F, Migliaro F, Sodano A, Umbaldo A, Romano A, Vallone G, et al. Can neonatal lung ultrasound monitor fluid clearance and predict the need of respiratory support? Critical care. 2012;16(6):R220. doi:

10.1186/cc11865. PubMed PMID: 23151314; PubMed Central PMCID: PMC3672599.

19. Cattarossi L, Copetti R, Poskurica B, Miserocchi G. Surfactant administration for neonatal respiratory distress does not improve lung interstitial fluid clearance: echographic and experimental evidence. Journal of perinatal medicine. 2010;38(5):557-63. doi: 10.1515/JPM.2010.096. PubMed PMID: 20629494.

20. Copetti R, Cattarossi L. The 'double lung point': an ultrasound sign diagnostic of transient tachypnea of the newborn. Neonatology. 2007;91(3):203-9. doi: 10.1159/000097454. PubMed PMID: 17377407.

21. Copetti R, Cattarossi L, Macagno F, Violino M, Furlan R. Lung ultrasound in respiratory distress syndrome: a useful tool for early diagnosis. Neonatology. 2008;94(1):52-9. doi: 10.1159/000113059. PubMed PMID: 18196931.

22. Federici M, Federici PV, Feleppa F, Gizzi C, Agostino R, Bellelli A, et al. Pulmonary ultrasonography in the follow-up of respiratory distress syndrome on preterm newborns. Reduction of X-ray exposure. Journal of ultrasound. 2011;14(2):78-83. doi: 10.1016/j.jus.2011.04.004. PubMed PMID: 23397012; PubMed Central PMCID: PMC3558044.

This article is protected by copyright. All rights reserved. 
23. Alrajhi K, Woo MY, Vaillancourt C. Test characteristics of ultrasonography for the detection of pneumothorax: a systematic review and meta-analysis. Chest. 2012;141(3):703-8. doi: 10.1378/chest.11-0131. PubMed PMID: 21868468.

24. Alrajab S, Youssef AM, Akkus NI, Caldito G. Pleural ultrasonography versus chest radiography for the diagnosis of pneumothorax: review of the literature and meta-analysis. Critical care. 2013;17(5):R208. doi: 10.1186/cc13016. PubMed PMID: 24060427; PubMed Central PMCID: PMC4057340.

25. Ku BS, Fields JM, Carr B, Everett WW, Gracias VH, Dean AJ. Clinician-performed Beside Ultrasound for the Diagnosis of Traumatic Pneumothorax. The western journal of emergency medicine. 2013;14(2):103-8. doi: 10.5811/westjem.2012.12.12663. PubMed PMID: 23599841; PubMed Central PMCID: PMC3628453.

26. Oveland NP, Sloth E, Andersen G, Lossius HM. A porcine pneumothorax model for teaching ultrasound diagnostics. Academic emergency medicine : official journal of the Society for Academic Emergency Medicine. 2012;19(5):586-92. doi: 10.1111/j.1553-2712.2012.01349.x. PubMed PMID: 22594363; PubMed Central PMCID: PMC3502747.

27. Wyman ML, Kuhns LR. Accuracy of transillumination in the recognition of pneumothorax and pneumomediastinum in the neonate. Clin Pediatr (Phila). 1977 Apr 16(4) 323-4..pdf>. Clin Pediatr. $1977 ; 16(4): 323-4$.

28. Kuhns LR, Bednarek FJ, Wyman ML, Roloff DW, Borer RC. Diagnosis of pneumothorax or pneumomediastinum in the neonate by transillumination. Pediatrics. 1975;56(3):355-60.

29. Donn SM. Historical Perspective: Neonatal Transillumination. NeoReviews. 2005;6(3):e112-e4. doi: 10.1542 . 


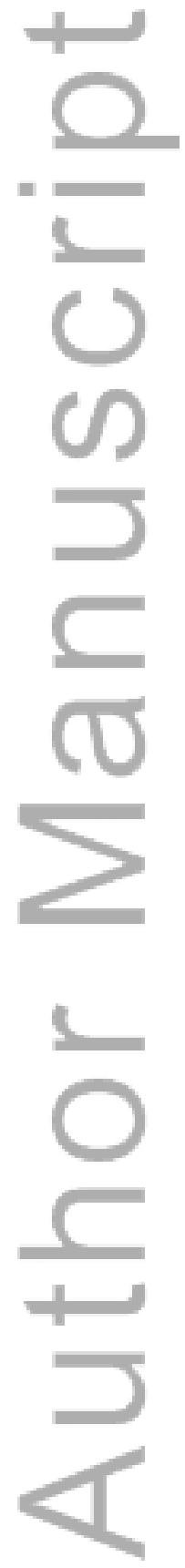


Table 1: Test characteristics of lung ultrasound to detect tension pneumothorax using the post-mortem examination as the "gold standard." LUS was interpreted prior to the autopsy was considered positive if there were A-lines with no lung sliding or B-lines on 2-D cine or if there was the "stratosphere" sign on M-mode. Postmortem exam was considered positive for tension pneumothorax if there was air displacing the diaphragm inferiorly on opening of the abdomen (tension pneumothorax), or if there was ongoing air leak seen while injecting the dissected lungs with up to $10 \mathrm{ml} / \mathrm{kg}$ of air with the lungs submerged underwater (bubble test). TP=true positive, $\mathrm{FP}=$ false positive, $\mathrm{TN}=$ true negative, $\mathrm{FP}=$ false negative, $\mathrm{PTX}=$ pneumothorax.

\begin{tabular}{|l|l|l|l|}
\hline & Autopsy (Tension PTX) & & \\
\hline LUS Test & Positive & Negative & \\
\hline Positive & $4=\mathrm{TP}(4$ Tension PTX) & $0=\mathrm{FP}$ & PPV (TP/(TP+FP) $=100 \%$ \\
\hline Negative & $0=\mathrm{FN}$ & $14=\mathrm{TN}$ & NPV (TN/FN+TN) $=100 \%$ \\
\hline & Sens (TP/(TP+FN) $)=100 \%$ & Spec $(\mathrm{TN} /(\mathrm{FP}+\mathrm{TN}))=$ & \\
& & $100 \%$ & \\
\hline
\end{tabular}


Table 2: Comparison of vital signs, respiratory parameters, and blood gas analysis between lambs prior to pneumothorax, lambs after pneumothorax was recognized, and lambs that never developed pneumothorax. Analysis conducted using a one-way ANOVA and Tukey post-hoc test. Post-hoc analysis: *=significant difference between Pre-PTX and Post-PTX, ${ }^{\star *}=$ significant difference between both Pre-PTX and Post-PTX and Pre-PTX and No-PTX. $\mathrm{FiO}_{2}=$ fraction of inspired oxygen, $\mathrm{SpO}_{2}=$ saturation of inspired oxygen, NIRS = near infrared spectroscopy, $\mathrm{PaO}_{2}=$ partial pressure of oxygen dissolved in arterial blood, $\mathrm{PaCO}_{2}=$ partial pressure of carbon dioxide dissolved in arterial blood, A-a gradient $=$ alveolar - arterial concentration of oxygen gradient, $\mathrm{EtCO}_{2}=$ end tidal carbon dioxide.

\begin{tabular}{|c|c|c|c|c|}
\hline & Pre PTX, $\mathrm{N}=4$ & Post PTX, N=4 & No PTX, N=5 & $P$ value \\
\hline Mean airway pressure $\left(\mathrm{cmH}_{2} \mathrm{O}\right)$ & $18 \pm 2.7$ & $17.8 \pm 2.9$ & $17.6 \pm 3$ & 0.98 \\
\hline Tidal volume $(\mathrm{ml} / \mathrm{kg})$ & $6.8 \pm 1.3$ & $6.8 \pm 1.3$ & $5.4 \pm 1.8$ & 0.33 \\
\hline $\mathrm{FiO}_{2}$ & $0.55 \pm 0.13$ & $0.9 \pm 0.2$ & $0.72 \pm 0.23$ & 0.08 \\
\hline Heart rate $(\mathrm{bpm})$ & $170 \pm 42$ & $84 \pm 64^{*}$ & $151 \pm 22$ & 0.047 \\
\hline $\mathrm{SpO}_{2}(\%)$ & $93 \pm 5$ & $63 \pm 20^{\star \star}$ & $93 \pm 2$ & 0.01 \\
\hline NIRS (\%) & $67 \pm 5$ & $57 \pm 12$ & $73 \pm 7$ & 0.06 \\
\hline Mean Arterial Pressure $(\mathrm{mmHg})$ & $49 \pm 7$ & $25 \pm 9^{\star \star}$ & $49 \pm 6$ & 0.00 \\
\hline $\mathrm{pH}$ & $7.21 \pm 0.1$ & $7.15 \pm 0.16$ & $7.11 \pm 0.17$ & 0.64 \\
\hline $\mathrm{PaO} 2(\mathrm{mmHg})$ & $38 \pm 11$ & $36 \pm 19$ & $40 \pm 7$ & 0.92 \\
\hline $\mathrm{PaCO} 2(\mathrm{mmHg})$ & $50 \pm 16$ & $62 \pm 11$ & $88 \pm 40$ & 0.17 \\
\hline A-a gradient $(\mathrm{mmHg})$ & $293 \pm 88$ & $600 \pm 21^{\star \star}$ & $351 \pm 137$ & 0.01 \\
\hline Oxygen index & $27 \pm 8$ & $52 \pm 22$ & $31 \pm 14$ & 0.11 \\
\hline Cerebral blood flow (ml/min) & $45 \pm 30$ & $27 \pm 19$ & $51 \pm 23$ & 0.36 \\
\hline $\mathrm{EtCO}_{2}(\mathrm{mmHg})$ & $37 \pm 30$ & $19 \pm 4$ & $26 \pm 7$ & 0.4 \\
\hline
\end{tabular}

This article is protected by copyright. All rights reserved. 


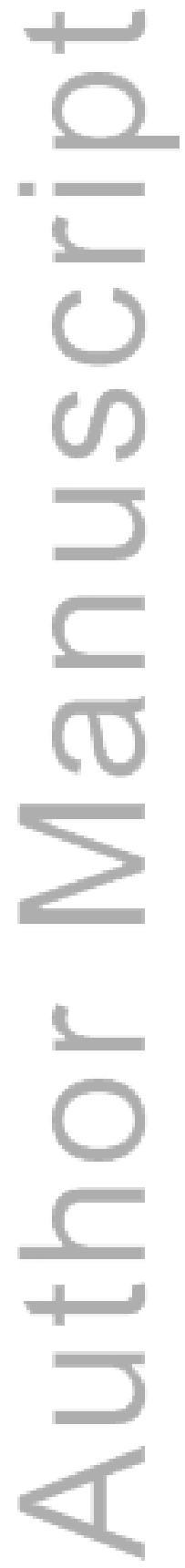


Figure Legends:

Figure 1: Negative pneumothorax on LUS and autopsy (A \& B) versus positive pneumothorax on LUS and autopsy (C \& D). A: LUS M-mode and 2-D images showing the "seashore sign" of "waves" on top hitting the "beach" underneath which represents normal lung sliding. The image also shows consolidated B-lines creating a white-out appearance of a lung with RDS (type 3). B: corresponding negative post-mortem gross examination of the lungs, the right and left diaphragm are clearly seen in contact with the lungs. C: the "seashore" is obliterated by horizontal lines creating the "stratosphere sign" on M-mode, difficult to see the pleural line and a lack of lung movement. The corresponding 2-D image shows A-lines with the absence of B-lines. A-lines with a lack of B-lines and no lung sliding indicates a pneumothorax. D: corresponding positive post-mortem gross examination, looking superiorly from the umbilicus of the lamb towards the inferior portion of the diaphragm/lungs, a tension pneumothorax seen on the right side of the chest with no evidence of tension pneumothorax of the left chest.

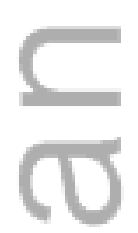

Figure 2: Example of a positive (A-C) and negative (D\&E) bubble test for ongoing air leak. The lungs and trachea were carefully dissected out of the chest. We replaced and secured a cuffed 4.0 endotracheal tube (ETT) into the intact trachea to create an air tight system. We then submerged the lungs in water and slowly injected into the ETT in a stepwise fashion until a maximum volume of $10 \mathrm{ml} / \mathrm{kg}$ was reached. A-C: positive bubble test depicting bubbles escaping from the right middle lobe with $3 \mathrm{ml} / \mathrm{kg}$ of air injected ( $A$ and $B$ ), the lungs rise slightly as up to $10 \mathrm{ml} / \mathrm{kg}$ is reached. D-E: negative bubble test. The unaerated lung sinks to the bottom of the container, with injection of $10 \mathrm{ml} / \mathrm{kg}$ of air, the lung rises to the top of the container. No bubbles are seen escaping indicating a negative test for ongoing air leak.

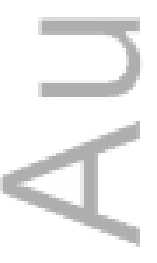


Figure 3: Post-mortem gross examination examples from the 2 subjects with false negative LUS exams for air leak syndrome (A \& B, subject 5 and $C \& D$, subject 8$)$. A: posterior view of whole lungs with negative findings prior to injection of air. B: close up of the posterior LUL showing PIE after injection of $5 \mathrm{ml} / \mathrm{kg}$, the bubble test was negative for ongoing air leak. C: anterior view of the lungs. Prior to injection of air, a bleb in the upper margin of the posterior aspect of the LLL was seen. After injection of $10 \mathrm{ml} / \mathrm{kg}$ of air, the LLL bleb is still difficult to see looking at the anterior view of the lungs. D: posterior view of the lungs with a large bleb early noted.

RUL=right upper lobe, RML=right middle lobe, RLL=right lower lobe, $L U L=$ left upper lobe, $L L L=l$ left lower lobe.

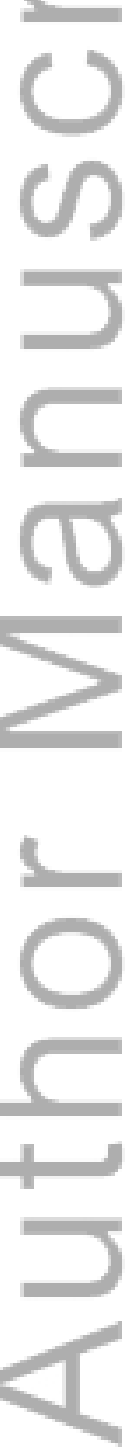



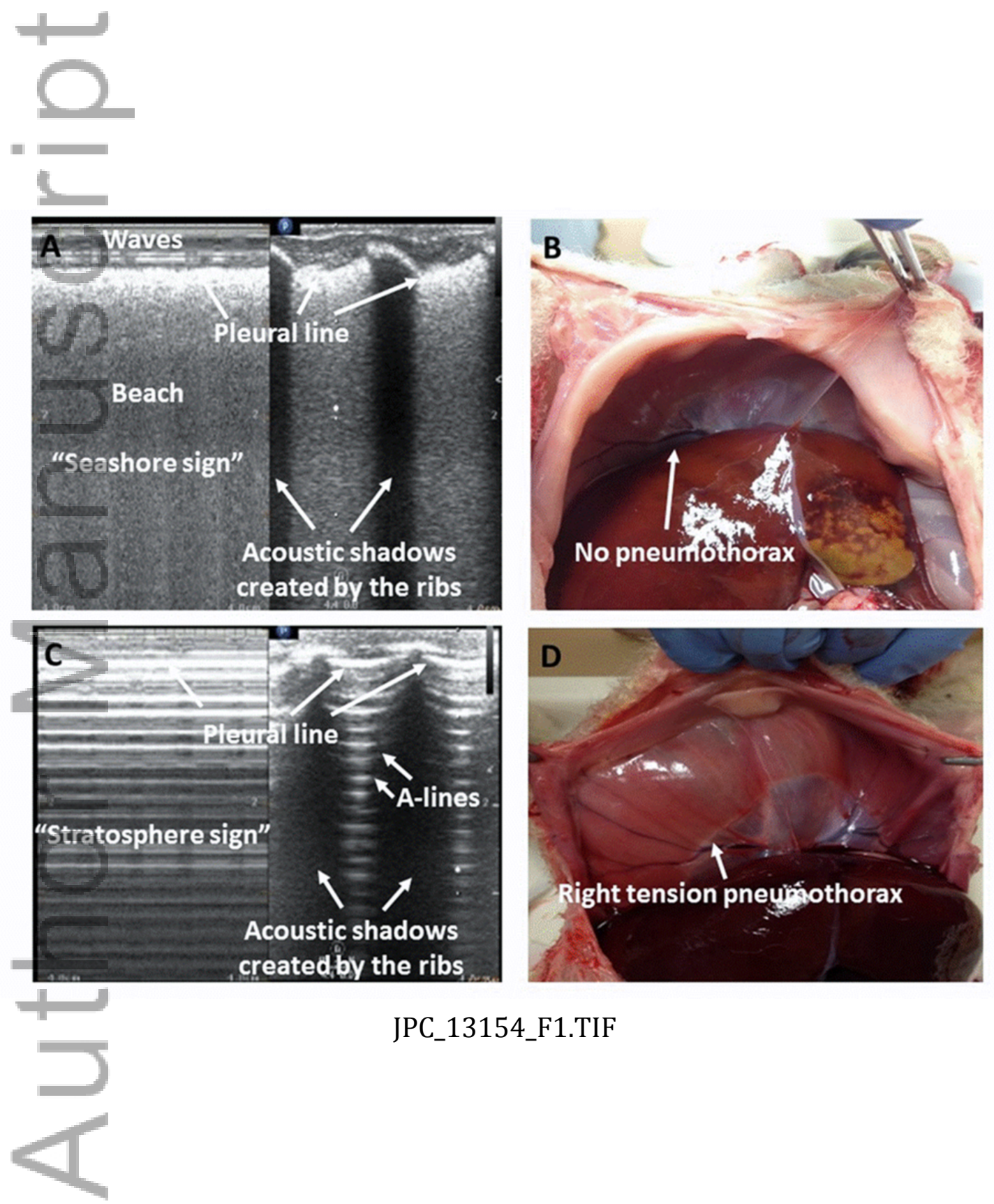

This article is protected by copyright. All rights reserved. 


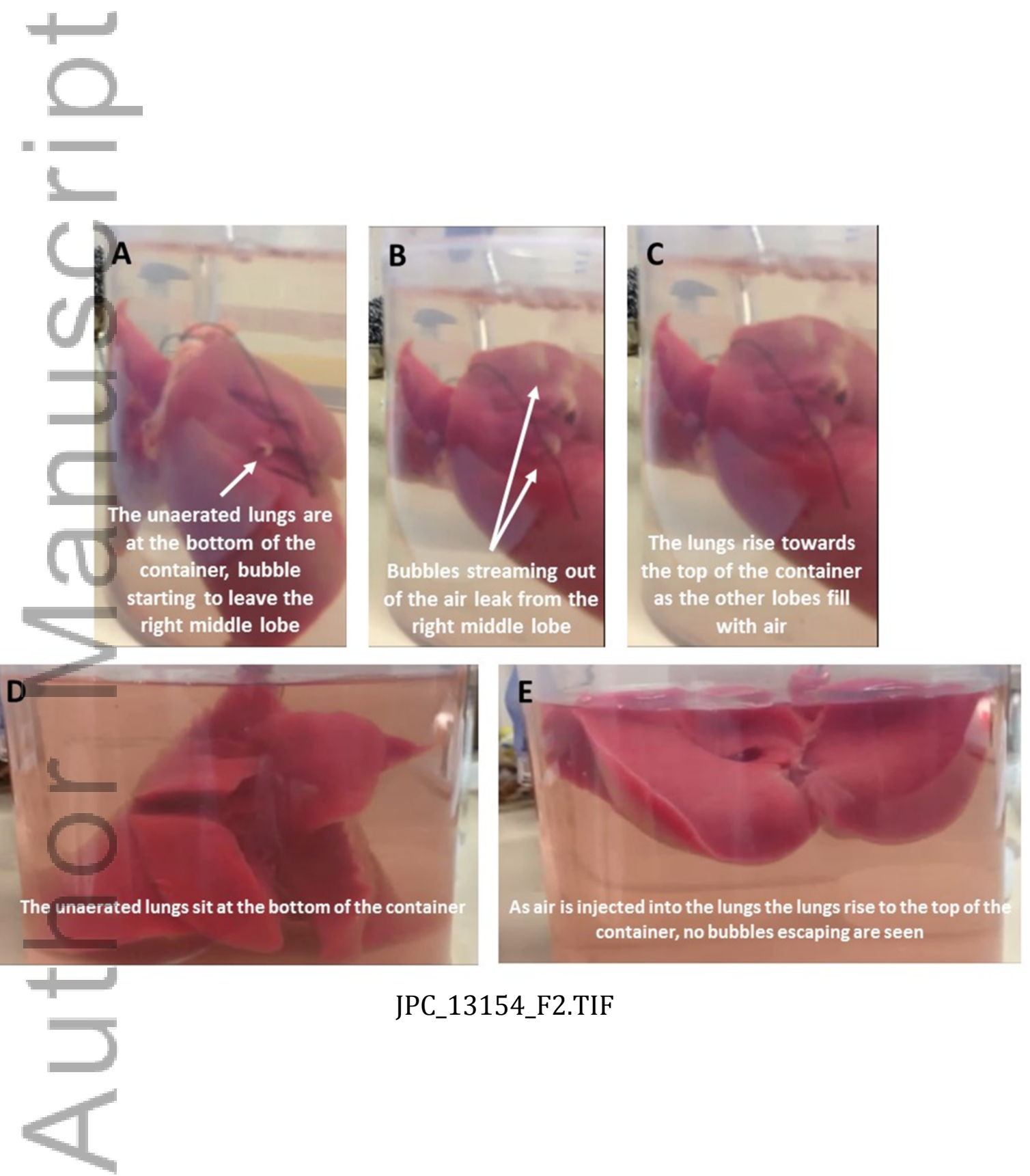

This article is protected by copyright. All rights reserved. 


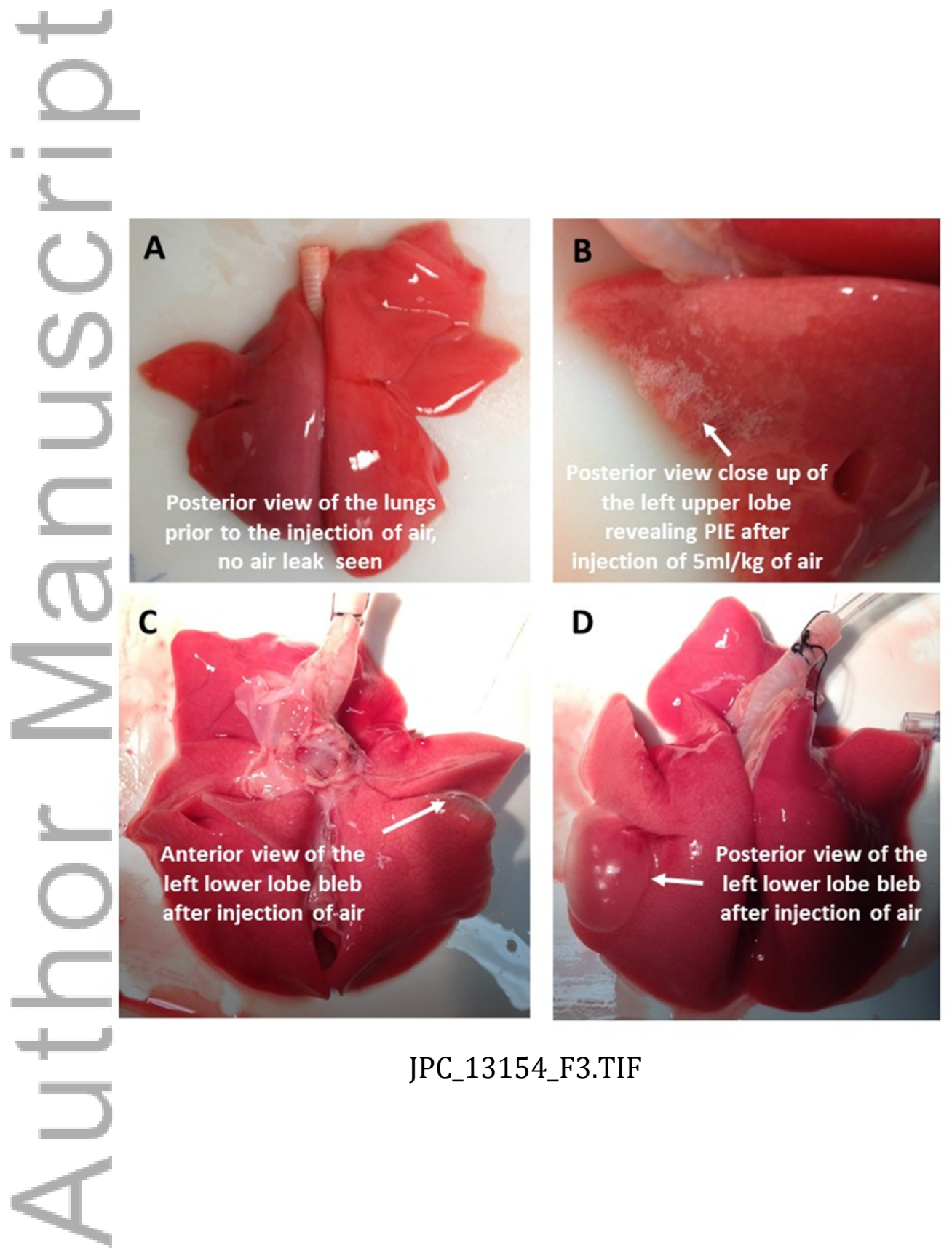

This article is protected by copyright. All rights reserved. 